\title{
Experiences of Placement Breakdown among Children and Youth with Behavioural Difficulties in the Foster Care System in Croatia
}

\author{
Ivana Galićc ${ }^{*}$, Slavica Blažeka Kokorić ${ }^{2}$ and Maja Laklija ${ }^{3}$ \\ ${ }^{I}$ Ivana Galić, social worker, Centre for Social Welfare Velika Gorica, Republic of Croatia, email: \\ ${ }^{2}$ Full Prof. Slavica Blažeka Kokorić, PhD, University of Zagreb, Faculty of Law, Social Work Study Centre, \\ Republic of Croatia \\ ${ }^{3}$ Assoc. Prof. Maja Laklija, PhD, University of Zagreb, Faculty of Law, Social Work Study Centre, Republic of \\ Croatia
}

\begin{abstract}
Many studies have shown different negative psychological and health-related consequences of frequent changes in placement affecting foster care children. There is also evidence that placement disruptions and child behavioural difficulties are interrelated. This qualitative research aims to provide insight into the experiences of children and the youth with behavioural difficulties regarding foster care placement breakdown. The research was conducted by using the semi-structured interview method. Interpretative phenomenological analysis was used to analyse the data. Eight male adolescents with behavioural difficulties who had experiences of placement changes from foster care to institutional care in Croatia were the participants included in this study. All of them had at last one experience of foster care placement breakdown. The results of this study showed that children and foster parents are not adequately prepared for foster care. Some of the participants experienced many problems in foster families: an unequal position between them and biological children of foster parents, a strong sense of non-acceptance and feeling of being left to themselves, violence, physical punishment, etc. The reasons for their withdrawal from placement in the foster family were physical violence, their negative behaviours and problems at school, conflict relationships in foster family, and discontinuation of foster care by foster parents. They recognised the need for improvement of certain aspects of the foster care system in Croatia (better education of foster parents for children with behavioural difficulties, better professional monitoring and supervision, improvement of quality of relationships in foster families, etc.).
\end{abstract}

Keywords: children and youth with behavioural difficulties, specialised foster care, placement breakdown

\section{Introduction}

The development of specialised foster care began in the 1970s in the US, Canada and the United Kingdom, with the aim of providing the best possible care for children with emotional, 


\section{5th International Conference on New Findings ON HUMANITIES AND SOCIAL SCIENCES}

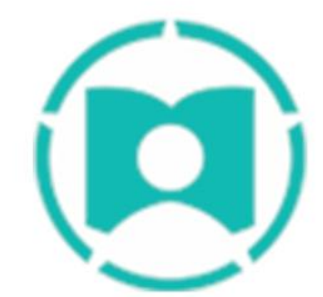

\section{0-22 NOVEMBER, 2020 \\ PARIS, FRANCE}

physical and mental difficulties, as well as behavioural difficulties (Laklija et al., 2012). A new Foster Care Act (OG 115/18) was adopted in the Republic of Croatia in 2018, in which a special category of "foster care as an occupation" was defined for the first time. Within this category of foster care, a form of specialised foster care is envisaged as part of which foster parents who have undergone further education provide placement services and more complex, specific care for children with behavioural difficulties and various severe health or developmental difficulties (Foster Care Act, OG 115/18, Laklija, 2011).

Specialised foster care for children with behavioural difficulties is still poorly developed in Croatia. According to the annual reports of the Ministry for Demography, Family, Youth, and Social Policy $(2016,2017), 11$ to 74 children and young people with behavioural difficulties are placed in foster care in Croatia every year.

Various studies show that the realisation of foster care for children with behavioural difficulties in Croatia is accompanied by numerous difficulties and frequent foster care placement breakdown. For example, the study conducted by Čičak (2016) found that experts on foster care point out that in this area in Croatia the problem of insufficient preparedness of foster parents and children for placement is still conspicuous. Furthermore, foster parents are insufficiently educated on how to deal with specific difficulties related to child's education (e.g. a child's problems at school) and upbringing, as well as the child's behavioural difficulties, and do not have sufficient access to professional help and support from institutions. On the other hand, foster children with behavioural difficulties often exhibit resistance when placed in a foster family and have difficulties with adapting to the new environment. They often face prejudice in the local community and at school, they experience failure in school, rejection by their peers, and a lack of acceptance by foster family members and the like.

Due to the present problems regarding the placement of children with behavioural difficulties in foster care and insufficient support provided by experts to foster children and foster family members, placement is often interrupted and children are transferred to another foster family or institutional care. Research conducted by Petrović and Laklija (2017) shows that foster care providers submit requests for termination of foster care due to disaccord with children, personal health issues, and the belief that they are unable to meet the children's needs due to the inability to cope with children's behavioural difficulties and fraught relationships with biological parents.

Given that there is a lack of research in Croatia on the experiences and perspectives of children and the youth with behavioural difficulties on foster care placement breakdown, this paper will present the results of a qualitative research on this topic. The research was conducted to enrich the knowledge and expand the understanding of the perspective of children and youth with behavioural difficulties regarding their experiences of foster care placement breakdown. In accordance with the stated research aim, the following research questions were posed: 1) From the perspective of children and youth with behavioural difficulties, what circumstances contributed to foster care placement breakdown? 2) What are the recommendations of children and youth with behavioural problems for the improvement of specialised foster care? 


\section{5th International Conference on New Findings On HUMANITIES AND SOCIAL SCIENCES}

\section{Methods}

A qualitative method was used in the research, and data was collected through the semistructured interview. The research was conducted on a sample of eight children and young people with behavioural difficulties who were placed in the Community Service Centre Zagreb (an institution specialising in meeting social and protection-related needs of children and the youth exhibiting behavioural difficulties) after foster family placement breakdown.

Intentional sampling was used in the selection of study participants. All research participants share a common experience of foster family placement breakdown and transfer from foster care to institutional care. All research participants are males. Participants' age ranged from 13 to 21, with an average age of 16.25 years.

Before conducting the research, the consent of the Ethical Committee of the Faculty of Law in Zagreb and the Ministry of Demography, Family, Youth and Social Policy was obtained, as well as the written consent for participation in the research provided by parents and research participants. Participation in the research was voluntary. The research was conducted in the premises of the institution where the research participants were placed. On average, the interviews lasted 45 minutes. Interviews were recorded and transcribed, and the statements of the participants were anonymised during the processing and presentation of the obtained research results.

The interpretative phenomenological analysis was used in the data analysis, which is aimed at a detailed examination of the participants' life worlds and seeks to examine personal experience and integrate it into personal perception and attitude about an object or event (Smith, 2004). The following textual markers were used in the presentation of the obtained results in this paper: The obtained categories within a particular research question are marked in bold text. Topics that appear within certain categories are marked by italics and bold, and are accompanied by quotations of participants' statements. The statements of the participants are given in parentheses in italics. An ordinal number of the research participant was recorded at the end of each statement. All categories and terms are narratively interpreted in the text.

\section{Results}

3.1 Circumstances contributing to the foster family placement breakdown of children and youth with behavioural difficulties

By analysing research participants' answers to the research question "From the perspective of a child/young person, which circumstances contributed to the foster family placement breakdown of children with behavioural difficulties?", the following categories were obtained: exposure to physical violence in the foster family, significant problems at school, expression of socially unacceptable behaviours, fraught relations between the foster family and the foster child, and withdrawal from foster care by foster parents.

As an important circumstance contributing to the foster family placement breakdown, the participants point out their experience of exposure to physical violence in the foster family. 


\section{5th International Conference on New Findings ON HUMANITIES AND SOCIAL SCIENCES}

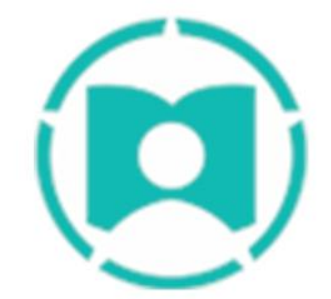

20-22 NOVEMBER, 2020

PARIS, FRANCE

Physical violence was manifest in corporal punishment by foster parents (»It was completely normal for them that children's legs are bruised blue because of caning or using a belt, or something like that... because they think it's for the good of children...I do not know of anything good about it..." (1)), as well as in physical abuse by foster parents' biological child ("In the first family, they oppressed me, beat me and similar... After a few days, as soon as I arrived, I figured out that things will not be good for me there, that their son will beat me, because I've already picked that up through my impression of him... Because of that boy, I requested the termination of placement... I said that I can no longer be in his presence there... "(6)).

As the reason for foster family placement breakdown, participants noted their problems at school that were manifest in poor grades ("I had poor grades..." (6), "Because of school problems... because I did not want to study..." (8)), neglecting school obligations (»I had significant problems regarded to school because I had no time to deal with it..." (1), "...I neglected school. The foster parent did not care at all about my school or anything..." (5)), skipping classes (»Since my foster parent forbade me from seeing my friends, I would be late for the first class because I was with them having a cup of coffee, or I would skip the last class... (5)", "I did not want to go to school. I mean, I went to school, but not every day..." (6)) and in fear of grade repetition ("I was scared that if I stayed, I would repeat the grade two times and I would no longer have the right to education anymore. The most significant problem was school, that is why I requested the termination of placement..." (5)).

Furthermore, research participants stated that another reason for the foster family placement breakdown was their socially unacceptable behaviour. In that sense, they described issues regarding their hyperactive behaviour ("Because I was hyperactive a lot..." (1)), the tendency towards involvement in fights (»Oh my, I used to beat up people every day at school, every single day, every day..." (1), "fights broke out at clubs...like I said, I was very problematic, terribly so. I used to get into fights daily, five/six times a day. It was a habit of mine (laughing)..." (2)) and consuming addictive substances ("I have been smoking since the fifth grade of primary school (laughing)...And then I started drinking, then doing drugs... I had some private "demons" of my own that I simply could not get rid of on my own. Then doing drugs started, gambling, all of it destroyed me...I used to see a psychiatrist because of addiction..." (2), "Since I started smoking pot then, also cigarettes and drinking..." (3)). Some participants stated that foster care placement breakdown was associated with frequent nights out and running away from the foster family ("going out and staying till late in the night...(2)", "I used to go out all the time and get into trouble...then I went away, I ran away...(3)", "...I was out all the time and yeah, I don't know...I took my shirts at night and all I had from the drier and I ran away..." (4)). One participant noted his issues related to the sale of drugs and police intervention, as well as the intervention by a social welfare centre ("A search of the house... I was sleeping and at two in the night special forces break into my room... that was like "boom", they took my mobile phone, checked all messages. Yes, I had messages about dealing and stuff like that..." (2)).

Among significant circumstances that resulted in the foster family placement breakdown, participants also noted problems regarding fraught, poor relations between themselves, and foster family members. The aforementioned was manifest in frequent arguments ("There 


\section{5th International Conference on New Findings ON HUMANITIES AND SOCIAL SCIENCES}

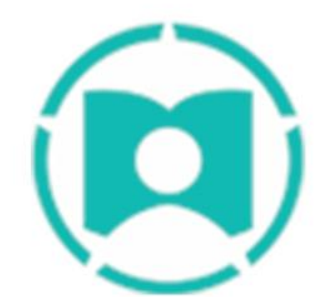

20-22 NOVEMBER, 2020

PARIS, FRANCE

were a lot of arguments, a whole lot in the first foster family...(2)", "We used to get into such a heated argument that I literally packed my things, I would not even say goodbye, I just left for another foster family...(4)", "I was forbidden from doing many things, we started getting into arguments more and more...(5)", "I had an argument almost every day..." (7)). Research participants stated that issues in their relationship with foster parents arose also due to frequent prohibitions ("I had girls come over in front of the building, and she did not allow it because of her faith... (3)", "They started forbidding me to do certain things, e.g. I was not allowed in the living room and so on... My foster parent forbade me from seeing a girl, she would also forbid me to use the Internet, she would not allow me anything..." (5)) and foster parents' request that they must adapt to their lifestyle ("They should have adapted to me, and not me to them because I was a child... (1)", "The problem is these first people were vegetarians. I was introduced to a totally catastrophic situation... After a few days I have already begun to adopt a little, but it took me a while..." (4)). Some participants experienced neglect from foster parents as foster children ("No, she did not take care... maybe she did the first few months, to show herself as I don't know what, but afterwards she did not...I missed being cared for, I did not want that lady to neglect me...(5)", "I expected that they would show more care, that they would care more... if I were asked, I would not want them to adopt anyone because I know the kind of people they are..." (8)) and unequal treatment of biological and foster children ("...in the foster family I had the experience of foster parents making a difference between their children and me... I mean, any foster parent would act to appreciate their children more than other children who are living under their roof... and that means the whole system does not work..." (1), "This was really noticeable, dad bought him a new mobile phone, he bought him this and that, while I did not get basically anything, not even something bought with money my foster parents received each month for me specifically..." (4)).

Fraught relations between foster parents and the foster child were also manifest in frequent expression of distrust of foster children on the part of foster parents ("Okay, I understand, I was a child and nobody trusted me about anything... Even my foster parent used to say to me "like you think anybody is going to trust you about anything", and I replied that I know nobody is going to trust me about anything..." (4), "It hurt me..., they did not trust us..." (8)), which in certain cases culminated in the foster parent giving up on the foster child ("Like they really gave up, their attitude was I don't care let him do what he wants to" (4)).

In the case of some research participants, foster family placement breakdown occurred due to a certain foster parent reasons for ceasing the activity of providing foster care. In this context, participants pointed out the situations involving withdrawal from the activity of providing foster care due to developmental difficulties of a biological child("... they had a child who was four years old and could not speak, the child had issues with speech and they were supposed to take him to a speech therapist, and do this and that..." (4)), relocation of the foster family to a foreign country("In the first family, the reason for foster care placement breakdown was the fact they were moving to Germany..." (7), "Now they are working in Switzerland, so we could not go with them..." (8)), the age of foster parents("The reason in the first family was they were too old and could not take care of us, I was in puberty so they faced problems related to that..." (8)) and the revocation of the license to engage in foster 


\section{5th International Conference on New Findings ON HUMANITIES AND SOCIAL SCIENCES}

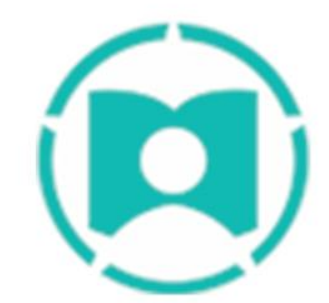

20-22 NOVEMBER, 2020

PARIS, FRANCE

care ("there was a termination of placement in the second family because their license for being foster parents was revoked...they can no longer be a foster family... "(7)).

3.2 Recommendations provided by children and the youth with behavioural difficulties for improving specialised foster care

Research participants who have experienced the foster care placement breakdown also provided certain recommendations for improving specialised foster care. By analysing research participants' responses to the fifth research question, namely: "What are the recommendations of children and youth with behavioural difficulties for the improvement of specialised foster care?", the following categories were obtained: better education and training of foster parents, continuous monitoring and supervision practised by experts over the foster family, development of a better foster care system, the necessity of altruistic motives on the part of foster parents for engaging in the foster care activity and adequate attitude of foster parents towards the foster child.

Research participants pointed out that better education and training of foster parents is necessary for improving the specialised foster care system. As part of this recommendation, participants noted the necessity of raising the awareness of the great responsibility of the foster parent for the foster child ("Foster parents need to be aware of what responsibility they carry when they receive children who are not their own. It is an even greater responsibility than when they take care of their children... (1)", "... that she is still responsible for me if something happens to me because on paper, it is like that... (3)".

They also pointed out the need for better training and preparation of foster parents ("Better training of foster parents is important..." (4), "If they are already 100\% sure that they will have someone as the foster child, since that is their will, then they should prepare for it because it's really not easy..." (8)) and the need for greater caution in issuing licenses for engaging in foster care ("It is important that the license is not given to some families, that is to rude, annoying, literally arrogant people... «(5)).

They also stated that it is desirable for the foster parents to have prior experience in parenting ("...I would like foster families to be families who already have experience in parenting since if it is so, then they know how to deal with children..." (1)).

Research participants also highlighted the necessity of continuous monitoring and supervision carried out by experts over the foster family. In this sense, they pointed out that carrying out checks of foster families should be more frequent ("It's terrible, she used to come over and stay fifteen minutes so she could see what the situation is like and that's it, nothing extraordinary. I think this is a big failure...." (2), "I think foster families should be checked as much as possible and in as many ways as possible... I have, I don't know... a social worker used to come over every three, four months, checks should be much more frequent, not every single day, but at least every month or two, that would be OK. But, if a social worker comes after half a year, this does not really make any sense..." (4), "She should have checked it all at first and ask around a bit about the family, and then decide on whether I should stay here or not..." (5) and that these checks are important in terms of gaining a realistic impression 


\section{5th International Conference on New Findings ON HUMANITIES AND SOCIAL SCIENCES}

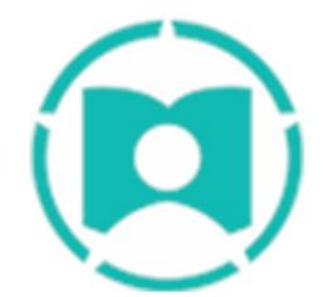

20-22 NOVEMBER, 2020

PARIS, FRANCE

of the atmosphere in and functioning of the foster family ("I would say that social workers should monitor what is happening there for at least four months, and they should check at least once every two weeks what the atmosphere is like there..." (1), "At that point they would actually see what the situation is like and how matters stand in the house..." (4)).

Furthermore, they pointed out that monitoring should be carried out in the form of personal conversations between experts and the foster child (...this is what I did not have the chance to do... to talk to each child in person, ask how they feel here..." (1)) and by means of unannounced visits to the foster family ("I think they should just come suddenly one day, without an announcement..." (4)).

As part of the recommendations for the development of a better foster care system, participants noted the necessity for greater care exercised by social welfare experts in connection with foster children ("Social services should care even more than foster parents for children they are responsible for..." (1)).

They also highlighted that the foster system should make it possible that all children in need are placed in foster care ("...it would be great if all those who need it are provided with an opportunity to stay in a foster family, to experience that life because I do not think they will regret it..." (3)). Participants also exhibited their attitude concerning the necessity of increasing the amount of funds received by foster parents for the purpose of meeting the needs of children in foster care ("The amount received by foster parents from social services for meeting the child's needs should definitely be increased... First, because that would make for a better quality of life, both for foster parents and foster children, and second because that would make things for foster parents easier and let them know that they can do more with the money and they would try harder when it comes to anything..." (2)). They pointed out that it is necessary to introduce a better review of the manner in which the funds are spent ("they receive some money monthly for each foster child...so spending all of the funds received for children should be checked..."(4)).

Based on their own experience, certain participants pointed out that prior to a child being placed in a foster family, a check should be performed to determine whether all household members agree on the desire to provide foster care ("...it is important that everyone, and I mean everyone, in that household agree with it. In my case, the situation was that I was placed in a family who did not in which not all members agreed with having me there. If all family members don't agree with it, they should not have foster children, to avoid issues like Ifaced..." (4)).

They also pointed out the necessity of better preparation and providing the child with information on foster care before placement, as well as acknowledging the child's opinion regarding the selection of a suitable foster family ("It is important they inform children better on what it means to be placed in a foster family..." (3), "Children should also be asked what they want specifically with regard to the family, what they expect the most and the like" (5), "...to think more logically about where a certain child could be placed, to observe behaviours of a boy or girl and to assess where placement would turn out for the best, and then to ask them what they think about all of it..." (8)). 


\section{5th International Conference on New Findings ON HUMANITIES AND SOCIAL SCIENCES}

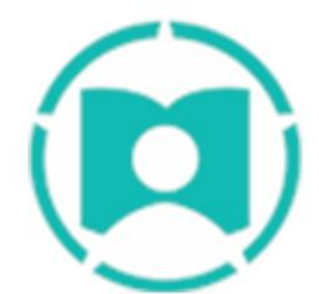

20-22 NOVEMBER, 2020

PARIS, FRANCE

According to the research participants' observations, experts should work more intensively with biological parents in order to improve the quality of the Croatian foster care system: ("Maybe they should have consulted more with my parents and work with them more..." (2)), and siblings should be placed in the same foster family for the aforementioned purpose: ("Yes, it would be very different if I were placed in the foster family along with my brother and sister from the very start (5)".

Another of the recommendations for improving foster care given by the participants involved stating that it is important that foster parents are primarily guided by altruistic motives with regard to engaging in foster care, whereby the key criterion for engaging in foster care should be precisely the desire of foster parents to help the foster child ("Do not become a foster parent for some benefit, but out of kindness and because you want to help someone...(2)", "It is important that the child feels you actually want to help them..." (3)) because being a foster parent should be motivated by love, and not money ("...that depends on the people, it is important that people who really love it and do it out of love rather than money become foster parents..."(3)).

Participants understood that the quality of the foster parents' relations with the foster child plays a very significant role in foster care. In this regard, they pointed out the importance of accepting the foster child as a family member ("...it is important that they are considered a family member..." (5)), as well as the importance of cultivating an equal relation on the part of foster parents with the biological and the foster child("Treat them as if they were your own...(1)", "...only if the foster parent accepted the child as their own..." (3), "...there is your own child and another person's child, that is the foster child, you have to treat them equally because the child will sense they are not an equal here and that something is wrong..." (4)).

Furthermore, they highlighted the importance of foster parents' commitment to caring for foster children ("Well, I think some foster parents should devote themselves to children to a greater extent. If you do not have the time to spend with them, it is better you refrain from being a foster parent...(2), "It is important that they take care of foster children like normal parents, and not neglect them...(5)", "...that they try to help them with school and so on...(6)", "I would like that they treat children better and be more caring..." (8)). They believe it is important that foster parents' make it possible for foster children to engage in leisure activities (»That I can practice football...that they let them train something if they want to, that they let them play videogames, that's about it... (6)".

Participants identified not only the importance of foster parents setting certain boundaries and encouraging discipline as part of foster child upbringing ("Try to be as strict as possible (laughing) not too strict, but strict enough that some boundary between foster parents and foster children is observed, not to have bedlam break out (laughing)..." (2)), but also the importance of foster parents allowing foster children to have a certain level of freedom and autonomy ("In the beginning it is quite good not to grant too much freedom to children until they get used to things and understand the kind of upbringing, but later, bit by bit, they should allow them some freedom in the sense of children going out and similar things..." (3). They also highlighted that foster parents should engage in conversation, and not violence when resolving issues with them ("I would like that everything is resolved by having a conversation, and not 


\section{5th International Conference on New Findings On HUMANITIES AND SOCIAL SCIENCES}

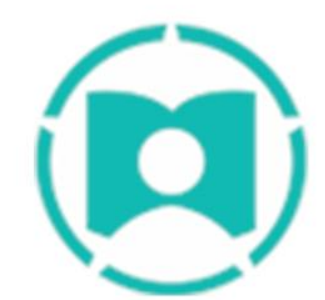

20-22 NOVEMBER, 2020

PARIS, FRANCE

by having someone hitting someone else..." (3), "I would say beating me should not have happened..." (6)).

They highlighted that, for the purpose of developing a good relationship between foster parents and foster children, it is desirable to organised group outings ("Eh, there should have been more of those outings, not being in the apartment all the time but travel somewhere when there is time... to see things and to experience some new situations..." (3)). They pointed out that expressing the feelings of love and care is important in foster families ("...in fact, love should be given in the foster family...(3)", "...it is important to show some love for the foster child, at least some level of it, it does not need to be anything special, but at least that the child notices they care...(4)", "I don't know, they should try harder to meet not only children's material needs, but also emotional, the feeling of love and such things..." (8)), and foster parents not giving up on the foster child is important("If you are engaging in caring for a foster child, you should at least try not to give up on it..." (4)).

\section{Discussion}

The results of this research confirmed that children and the youth with behavioural difficulties in foster families are often exposed to fraught, conflict-ridden relationships and inappropriate parenting methods, which on certain occasions includes physical violence and emotional degradation of the foster child. Inadequate parenting methods pose a risk to the child, as well as neglect of the child's needs and the use of funds intended for the foster child for other family needs (Čičak \& Laklija, 2018). It is interesting to note that the results of this research demonstrated that children and the youth with behavioural difficulties show a high level of selfcriticism in terms of their own socially unacceptable behaviours and that they are aware of their difficulties in fulfilling school obligations and mastering the school curriculum. This is in line with the results of previous research (Armsden et al., 2000, Dubowitz et al., 1994, cited in Laklija, 2009), which showed that school achievement of approximately half of foster children is below average and that foster children face a higher degree of difficulty in fulfilling school obligations. Dissatisfaction with the behaviours of foster children in the school and family environment is an additional source of stress and dissatisfaction for the foster parents themselves, and it often leads to an escalation of conflicts between foster parents and foster children. Such situations require increased involvement of foster parents in the upbringing of the foster child with behavioural difficulties (Čičak, 2016). Foster parents are often insufficiently educated and prepared for the behavioural difficulties of a foster child and are not always ready to devote the extra time, effort and energy that need to be invested in raising a child with behavioural difficulties. Furthermore, they often exhibit unwillingness in terms of self-sacrifice and adaptation of their parenting style and family values, habits and rituals, which can ultimately lead to the foster care placement breakdown (Timmer et al., 2004).

Research conducted by Khoo and Skoog (2014) about foster parents' experiences of the events surrounding the unexpected ending of a child's placement in their care, shows that many problems are associated with placement instability and breakdown: a lack of knowledge about the child's needs, insufficient understanding of the placement process, a difficult relationship 


\section{5th International Conference on New Findings On HUMANITIES AND SOCIAL SCIENCES}

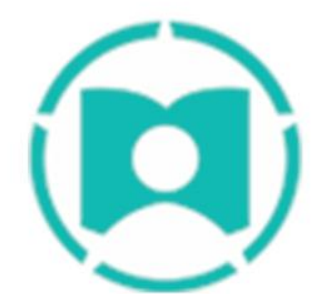

20-22 NOVEMBER, 2020

PARIS, FRANCE

with the social worker, and a lack of individualised service with the right supports at the right time.

The results of this research showed that, from the perspective of children and the youth with behavioural difficulties, there are various problems regarding the existing foster care system in Croatia. Based on their personal experience, the participants in this research provided numerous recommendations for improving the existing foster care system. They emphasised the importance of better preparation and education for training foster parents in high-quality child care, the importance of experts carrying out more frequent and continuous monitoring/control over foster families, the importance of engaging in foster care based on altruistic motives and the importance of foster parents developing a proper relationship with the foster child. The importance of the feeling of inclusion and belonging to a foster family was demonstrated by the research conducted by Žižak et al. (2012), which confirmed that the inclusion of foster children in everyday family life and participation in family decision-making strengthens the sense of belonging and has a positive effect on the child's sense of security, and thus on successful adaptation to foster care.

The need to improve the foster care system for children in Croatia was also indicated by a recent analysis conducted by the NGO Centre Sirius (2017) as part of the CareComp project. The results of this study showed that the trend of deinstitutionalisation in Croatia has encouraged the transfer of more children from institutional care to foster families, which is often carried out without proper preparation and support, which in turn leads to frequent foster care placement breakdown and return of children to institutions. Experiences of frequent relocation of a child from one type of placement to another have a detrimental effect on a child's upbringing and development, including a reduced ability to develop high-quality, more lasting emotional connections. Furthermore, the experience of failed foster care provision to a particular child often results in foster parents withdrawing from providing foster care altogether, thus reducing the number of available foster parents (Centre Sirius, 2017).

Furthermore, regarding the motives for foster care, the statements of the participants in this research offer the insight that they recognise many problems that arise if foster parents are engaged in foster care primarily for financial gain. They emphasise the importance of altruistic motives for foster care. Previous research has shown that the most prominent motive for foster parents engaging in foster care is precisely altruism and love for children, but there are also other motives and personal reasons, such as the need to fill a void or deal with a sense of loneliness in life (Sabolić \& Vejmelka, 2015). Other authors also point out that foster parents should be guided by the love and desire to help children without adequate parental care as a key motive for engaging in foster care (Žižak et al., 2012).

Regarding the importance of high-quality education and monitoring of foster families, the results of previous research have also shown that Croatia lacks a well-organised system of support for foster parents provided by professional services, which contributes to the phenomenon of burnout happening sooner to foster parents, as well as withdrawal from providing foster care (Čičak \& Laklija, 2018). Therefore, various authors point out that it is important to provide foster parents with various forms of help and support, such as organised parenting skills training, empowerment in the form of available ongoing support throughout the 


\section{5th International Conference on New Findings ON HUMANITIES AND SOCIAL SCIENCES}

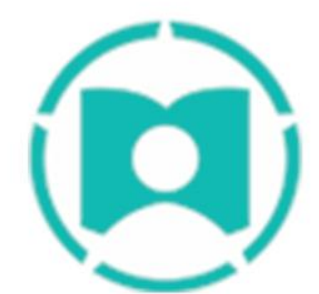

20-22 NOVEMBER, 2020

PARIS, FRANCE

whole week, more frequent home visits by child care professionals, better access to supervision, opportunities to participate in weekly meetings of support groups and the like (Chamberlain, 2003).

In order to prevent the foster care placement breakdown, it is necessary to ensure legal and personnel conditions for a high-quality process of selection and education of foster parents, pairing of children and foster parents, timely information provision and the development of high-quality and comprehensive individual change plan to respond to the foster child's needs. It is also important to include children and foster parents in the process of monitoring and evaluating the outcomes of foster care, as well as to provide timely support to the child and foster parents (Petrović \& Laklija, 2017).

Summarizing the results of this research on the experiences of children and the youth with behavioural difficulties concerning their life experience in foster families and the circumstances that led to the termination of foster care, it can be concluded that there are many challenges in the current foster care system in Croatia that require continued and systematic intervention. In addition to the improvement of specialised foster care for children and the youth with behavioural difficulties, it is important to encourage the development of professional foster care, which is defined as a special form of foster care by the Foster Care Act (OG 115/18). It would be worthwhile to promote, as well as carefully and thoughtfully introduce a special form of treatment foster care as it exists in Western European countries, the United States and Canada (Laklija, 2009). In addition to the above-mentioned, it is certainly important to focus professional work on better monitoring of foster families, more intensive work with biological parents, as well as preventive and treatment work with children in the school system since schools are a very important link in the development and empowerment of children and the youth from families at risk. There is certainly ample room for future improvements in all of these areas of professional activity of social workers.

\section{Conclusion}

This paper presents the results of qualitative research on the various experiences of children and the youth with behavioural difficulties regarding the circumstances that led to the foster care placement breakdown. The obtained results show that specialised foster care for children with behavioural difficulties in Croatia has not been sufficiently developed so far. The results indicate the need to improve certain segments of foster care in Croatia in order to prevent negative experiences and instances of foster care placement breakdown and return of children and the youth with behavioural difficulties to institutional care. This is extremely important when it is taken into consideration that such negative experiences cause additional trauma and increase developmental risks in this vulnerable population of children and the youth. On the other hand, they also lead to adverse consequences in the form of loss of motivation and a decrease in the number of foster parents who are willing to dedicate themselves to foster care for children with behavioural difficulties.

Given that the field of foster care for children with behavioural difficulties in Croatia is a field in which insufficient research was conducted, and very little is known about the 


\section{5th International Conference on New Findings ON HUMANITIES AND SOCIAL SCIENCES}

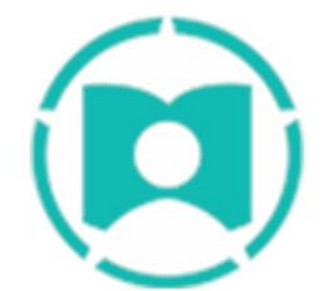

\section{0-22 NOVEMBER, 2020 \\ PARIS, FRANCE}

experiences of foster care placement breakdown from the perspective of children with behavioural difficulties, the results of this research facilitate a better insight into this set of difficulties that have been insufficiently examined so far. The results have special value since they are based on participatory research. By involving them in such research, the message for the vulnerable group of children and the youth with behavioural difficulties is that their experience with foster care is important and valuable, and that their opinion is wanted and valuable. Furthermore, this research has practical value because the results indicate specific difficulties encountered by participants during foster care placement. The results also provide specific guidelines for possible shifts in the quality of alternative care for children with behavioural difficulties.

In future research, it would certainly be important to further explore the perspective of foster parents regarding the experience of providing foster care to children and the youth with behavioural difficulties in Croatia. In addition, it would be useful to involve in the research the population of children and the youth with behavioural difficulties who are still placed in foster families. It would be especially worthwhile to gain knowledge on this topic from longitudinal research, which is currently lacking in Croatia, because adults who have experienced placement in specialised foster families for children and the youth with behavioural difficulties can certainly be an important and valuable source of information regarding the manner in which it is possible to effectively help this vulnerable population and make life in alternative care arrangements easier for them.

\section{References}

Armsden, G., Pecora, P. J., Payne, V. H., \& Szatkiewicz, J. P. (2000). Children placed in longterm foster care: An intake profile using the Child Behavior Checklist/4-18. Journal of Emotional and Behavioral Disorders, 8(1), 49-64.

Centre Sirius (2017). Analysis of community-based child protection system and foster parenting: An analysis of needs for in-service training of carers, educators and foster parents with special focus on transversal competencies. Final report (CareComp project). Centre Sirius, Zagreb.

Chamberlain, P. (2003): Treating chronic juvenile offenders: Advances made through the Oregon multidimensional treatment foster care model. American Psychological Association, Washington, DC.

Čičak, I. (2016). The challenges of foster care for children with behavioural disorders from a perspective of experts. Graduation thesis. Faculty of Law, Social Work Study Centre, Zagreb.

Čičak, I. and Laklija, M. (2018). Foster Care for Children with Behaviour Problems from the Perspective of Experts. Social themes: The Journal of theory and practise of Social Work and other akin Sciences, vol. 1 (5), pp. 27-54. 


\section{5th International Conference on New Findings ON HUMANITIES AND SOCIAL SCIENCES}

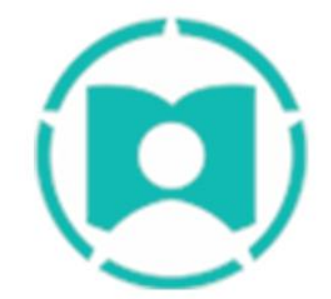

\section{0-22 NOVEMBER, 2020 \\ PARIS, FRANCE}

Khoo, E. and Skoog, V. (2014). The road to placement breakdown: Foster parents' experiences of the events surrounding the unexpected ending of a child's placement in their care. Qualitative Social Work, vol. 13(2), pp. 255-269.

Laklija, M. (2009). Challenges of foster care for children with emotional problems and behavioural disorders in the Republic of Croatia. Criminology \& Social Integration, vol. 17(2), pp. 1-138.

Laklija, M. (2011). Foster care models in Europe-results of a conducted survey. Forum for quality foster care of children, Zagreb. [Online]. Available: https://udomiteljizadjecu.hr/wpcontent/uploads/documents/publikacije/Foster\%20care\%20models\%20in\%20Europe\%20$\% 20$ results\%20of\%20a\%20conducted\%20survey\%20-\%20Maja\%20Laklija.pdf

Laklija, M., Vukelić, N. and Milić Babić, M. (2012). Specialised foster care for children with disabilities - foster carers' experiences. Croatian review of rehabilitation research, vol. 48(2), pp. 109-123

Ministry of Demography, Family, Youth and Social Policy (2016). Annual statistical report on beneficiaries and applied social welfare rights in the Republic of Croatia in 2016. [Online]. Available:https://mdomsp.gov.hr/pristup-informacijama/statisticka-izvjesca1765/statisticka-izvjesca-za-2016-godinu/2290.

Ministry of Demography, Family, Youth and Social Policy (2017). Annual statistical report on beneficiaries and applied social welfare rights in the Republic of Croatia in 201t. [Online]. Available:https://mdomsp.gov.hr/pristup-informacijama/statisticka-izvjesca1765/statisticka-izvjesca-za-2017-godinu/4505.

Petrović, L. and Laklija, M. (2017). The number of children placed in institutions for children without parental care - How the process of deinstitutionalization flows? In: Popović, S. and Zloković, J. (Eds.), Children and young people in alternative care: protection of the right to health. Faculty of Humanities and Social Sciences, Rijeka, pp. 10-27.

Sabolić, T. and Vejmelka, L. (2015). Foster care of children in Croatia from the perspective of foster parents and experts. Holon, vol. 5(1), pp. 6-42.

Smith, J. A. (2004). Reflecting on the development of interpretative phenomenological analysis and its contribution to qualitative research in psychology. Qualitative Research in Psychology, vol. 1(1), pp. 39-54.

Timmer, S. G., Sedlar, G. and Urquiza, A. J. (2004). Challenging Children in Kin Versus Nonkin Foster Care: Perceived. Costs and Benefits to Caregivers. Child Maltreatment, vol. 9(3), pp. 251-262

Foster Care Act. Official Gazett, no. 115/2018.

Žižak, A., Koller-Trbović, N., Jeđud Borić, I., Maurović, I., Mirosavljević, A. and Ratkajec Gašević, G. (2012). What do Children Say About Foster Care - Children's Perspective of Foster Care with Recommendations. UNICEF, Zagreb. 